\title{
Effect of Different Molecular Weight and Concentration of Polyethylene Glycol (PEG) on Tensile and Morphology of Sago Starch Film
}

\author{
Norzita Yacob ${ }^{1,3 *}$, Mohd Reusmaazran Yusof ${ }^{1}$, Maznah Mahmud ${ }^{1}$, Ainun Zuriyati Mohamed² and Khairiah Hj. Badri3 \\ ${ }^{1}$ Malaysian Nuclear Agency (Nuclear Malaysia) Bangi, 43000 Kajang, Selangor, Malaysia \\ ${ }^{2}$ Institute of Tropical Forestry and Forest Products (INTROP) University Putra Malaysia, 43400 UPM Serdang, \\ Selangor, Malaysia \\ ${ }^{3}$ Department of Chemical Sciences, Faculty of Science and Technology, National University of Malaysia, 43600 Bangi, \\ Selangor, Malaysia
}

\begin{abstract}
Sago starch is a seasonal based plantation and widely found in Asia country. Its application mainly in cooking such as biscuits and as a thickener in jellies. To further utilise its application, bioplastic from sago starch was developed. In this study, sago starch films were prepared through a blending and casting method using polyethylene glycol (PEG) as a plasticiser by varying its molecular weights and concentrations. The interaction between starch and PEG in the blend was studied using FTIR technique. The effect on transparency, tensile stress, Young's modulus as well as elongation percentages of the films was also examined. The results suggested that the addition of low molecular weight PEG (400 g.mol-1) increased the tensile stress of sago films from 33.51 MPa up to 39.11 MPa. Nevertheless, incorporation of high molecular weight of PEG (4000 g. $\mathrm{mol}^{-1}$ ) decreased the tensile strength of the film. Tensile strength and elongation at break of sago films increased with increasing of PEG concentration up to $2 \%$ and decreased with further increased of PEG content. Results indicated that there was a miscibility between these two components.
\end{abstract}

Keywords: sago starch film; tensile strength; elongation; Young's Modulus; PEG

\section{INTRODUCTION}

Petroleum based plastic has been widely used in many applications due to its superior properties. However, a huge amount of garbage is generated daily. This waste is composed of many different types of material which are not biodegradable (Kowalczyk et. al., 2014; Laohakunjit \& Noomhorm 2004). In recent years, bioplastic has received increasing attention as a potential alternative to petroleum based materials (Davis \& Song, 2006). Starch and cellulose are among the most promising materials in producing bioplastic because of their availability, renewable, biodegradable and low cost (Sahari et al., 2014). It is used in many applications especially in packaging, shopping bags and agricultural industry. Many studies have been reported on starch based films from various sources such as yam (Mali et al., 2002), pea starch (Saberi et al., 2016) and cassava (Suppakul et al., 2013). Sago starch is one of starch material that has similar physicochemical properties to other starches (Aminian et. al., 2013; Abdorreza et al., 2012) but less employed and underutilised.

Sago starch is extracted from sago palm and usually used in cooking. Unlike other starch which is derived from cereals (corn, wheat, rice), tubers (potato) and root (cassava), sago starch is derived from the stem of a sago palm. It is reported that sago starch yield could be higher than rice, corn or wheat and cassava (Karim et al., 2008). It grows well in peat soil and widely found in Asia especially in Malaysia, Indonesia, Thailand and Papua Guinea. Several reports on properties of sago starch as biofilm has been established (Ismail \& Zaaba 2012; Nouri \& Nafchi 2014). However, problems such as 
brittleness and less resistance to water restricted its application.

Plasticisers are generally used to overcome the brittleness of films, to improve flow and flexibility, increase toughness and prevent them from cracking during packing and transportation. Polyethylene glycol (PEG), sorbitol and glycerol are among plasticisers used to improve the properties of the starch film. The incorporation of glycerol in wheat gluten film improved film flexibility and reduced film puncture strength. Whereas, tensile strength of potato peel film decreased but increased elongation at break as concentration of glycerol increased (Kang \& Min 2010). PEG is a water soluble polymers with $-\mathrm{CH}_{2} \mathrm{CH} 2 \mathrm{O}$ - repeating groups with two $-\mathrm{OH}$ end groups. $\mathrm{PEG}$ with low molecular weight $\left(<1000 \mathrm{~g} \cdot \mathrm{mol}^{-1}\right)$ exhibits in clear, viscous form while high molecular weight PEG are white powder or flakes. Kim et al. (2009) reported PEG with a molecular weight less than 8 ooo $\mathrm{g} \cdot \mathrm{mol}^{-1}$ effectively used for starch plasticiser. Study on sago starch plasticised with a combination of sorbitol/glycerol found that seal strength can be improved (Abdorreza et al., 2011). Meanwhile, elongation at break increased while tensile strength decreased with the addition of glycerol and PEG (Ismail \& Zaaba 2012). Although there were many reports on the effect of incorporation PEG combine with other plasticisers on mechanical properties of starch film, to date, studies on the incorporation of PEG alone into sago starch film are not well explored. Therefore, the objective of this study is to investigate the effect of different molecular weights and concentrations of PEG on mechanical properties of sago starch film.

\section{MATERIALS AND METHOD}

\section{A. Materials}

Sago starch was obtained from Ng Kia Heng Sago Industry Sdn Bhd (Batu Pahat, Johor). PEG-40o, PEG-100o and PEG4000 were purchased from Sigma Aldrich. All chemicals were used as received.

\section{B. Film Preparation}

Preparation of sago starch film based on a research studied by Zailan et al. (2017). Sago starch 4\% (w/w) was chosen because the resulting film was uniform and not too brittle.
Sago starch was added to distilled water followed by heating at $90{ }^{\circ} \mathrm{C}$ for starch gelatinisation prior to stirring continuously for $45 \mathrm{~min}$ to complete homogeneity and gelatinisation in solution. PEG 400, 1000 and $4000 \mathrm{~g} \cdot \mathrm{mol}^{-1}$ (PEG-400, PEG-100o and PEG-400o, respectively) was added at the concentration of $2 \% \mathrm{w} / \mathrm{w}$, (starch basis). A $25 \mathrm{~g}$ of solution mixture was poured into a $10 \times 10 \mathrm{~cm}$ plastic mould. Then the film was dried in an oven at $40{ }^{\circ} \mathrm{C}$ for $48 \mathrm{~h}$ and peeled off after drying and kept at $23 \pm 2{ }^{\circ} \mathrm{C}$ and $50 \pm 5$ \% relative humidity $(\mathrm{RH})$ until tested. The samples were labelled as S for sago 4\% film, S/P400 for sago and PEG-40o blend, S/P10oo for sago and PEG-10oo blend and S/P400o for sago and PEG-400o blend. The same procedure for preparing starch film was applied for investigating the effect of different concentration of PEG.

\section{Film Thickness}

The thickness of each film was measured at five different locations and recorded to the nearest $0.001 \mathrm{~mm}$ with a digital micrometre (Mitutoyo, Japan). The thickness was determined according to Pirsa et al. (2020).

\section{Moisture Content}

The films of $20 \times 20 \mathrm{~mm}$ were dried at $105^{\circ} \mathrm{C}$ for $24 \mathrm{~h}$ and conditioned in a desiccator. The samples were weighed periodically until they reached a constant weight. The measurements were made in triplicate. Moisture content was calculated by the following formula:

$$
\mathrm{M}_{\mathrm{c}}, \%=\frac{W_{i}-W_{f}}{W_{i}} x 100
$$

where $W_{f}$ is a final weight of the sample and $W_{i}$ is an initial weight of the sample.

\section{E. Fourier Transform Infrared (FTIR) Spectroscopy}

FTIR was used to study the interaction between sago starch and PEG. The IR spectrum was recorded using FTIR (Bruker Tensor II, Germany) with attenuated total reflectance (ATR) at a wavelength of $4000-500 \mathrm{~cm}^{-1}$ with a scanning resolution of $2 \mathrm{~cm}^{-1}$. 


\section{F. Tensile Properties}

Tensile stress, Young's modulus and percentage elongation were measured according to ASTM D 882-97. The testing was conducted using a $20 \mathrm{~N}$ load cell (Model UUK 5, Korea) equipped with Ezi Step micro stopper motor system (Fastec, Korea). The sample was run at crosshead speed of $3 \mathrm{~mm} / \mathrm{min}$.

\section{G. Morphology Examination}

Field Emission Scanning Electron Microscope (FESEM), Carl Zeiss model Gemini SEM 500 was used to investigate the morphology of surface and cross section for all samples. Images were acquired at $500 \times$ magnification for surface and $1000 \times$ for cross section examination.

\section{H. Light Transmittance}

The light transmittance of films was measured using hazemeter spectrophotometer model BYK Gardner according to the standard method ASTM D1003. Films with $10 \times 10 \mathrm{~cm}^{2}$ dimension were used and five replicate measurements were recorded.

\section{RESULTS AND DISCUSSION}

\section{A. Moisture Content}

Figure 1 shows moisture content of sago film and its blend at different molecular weight. Moisture content of the films increased as PEG incorporated into the film. This can be explained by the presence of hydroxyl group in PEG that leads to the increase in $\mathrm{OH}$ group as displayed in FTIR spectrum (Figure 2). At ambient temperature, PEG-400 and PEG-1000 are liquids while PEG-400o is solid. These physical properties depend on the molecular weight. S/P40o demonstrated the highest moisture content due to the fact that PEG-40o is a liquid form which has higher hydroxyl group as compared to the high molecular weight of PEG (Kime et al., 2009).

S/P10oo has been used to study the effect of PEG concentration due to the highest tensile properties performed by $\mathrm{S} / \mathrm{P} 1000$ as discuss later in Table 1 . As illustrated in Figure 2, the moisture content increased as the concentration of PEG increased due to the increase in $\mathrm{OH}$ group exhibits in PEG.
Results are consistent with other research data (Kowalczyk et. al., 2014; Laohakunjit \& Noomhorm 2004).

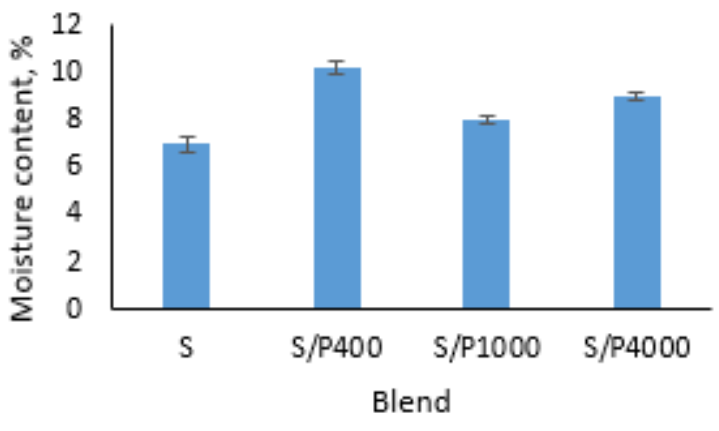

Figure 1. Effect of different molecular weight PEG on moisture content starch films

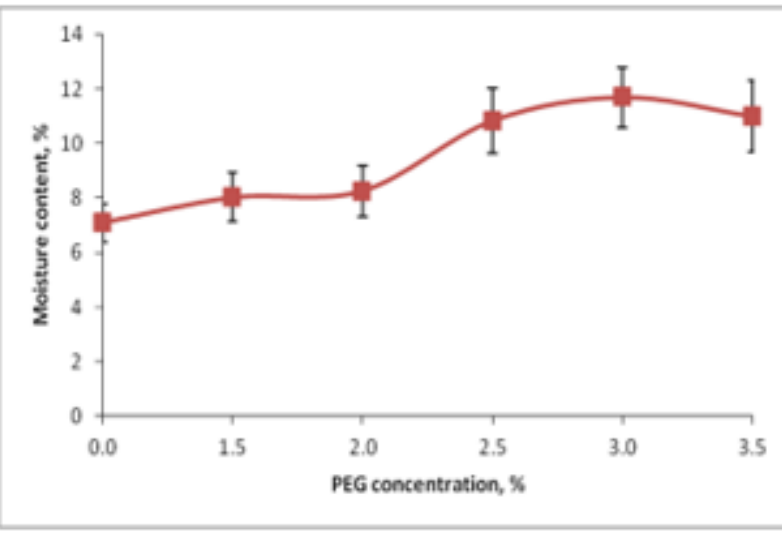

Figure 2. Effect of different concentration of PEG on the moisture content of S/P1000 


\section{B. Fourier Transform Infrared (FTIR) Spectroscopy}

Figure 3 shows the infrared spectrum for S, PEG-1000 and $\mathrm{S} / \mathrm{P} 1000$ films. As can be seen from the spectrum, the peak at $3280 \mathrm{~cm}^{-1}$ was due to $\mathrm{O}-\mathrm{H}$ stretching vibration. The peak at region $2924 \mathrm{~cm}^{-1}$ attributed to $\mathrm{C}-\mathrm{H}$ stretching whereas at $1640 \mathrm{~cm}^{-1}$ is assigned for water molecule which binds to sago starch molecule. The peak at wavenumber $1149 \mathrm{~cm}^{-1}$ and 1078 $\mathrm{cm}^{-1}$ correspond to $\mathrm{C}-\mathrm{O}$ stretching of $\mathrm{C}-\mathrm{O}-\mathrm{H}$ group. Another peak at 996 indicates $\mathrm{C}-\mathrm{O}$ stretching of $\mathrm{C}-\mathrm{O}-\mathrm{C}$ from the glycosidic linkage of starch (Ma et. al., 2009; Yaacob et. al., 2011; Jamingan et al., 2015). The corresponding peaks for PEG-100o are observed at 3418, 2873, 1455, 1349, 1249 and $1086 \mathrm{~cm}^{-1}$ indicates $\mathrm{O}-\mathrm{H}$ stretching, C-H stretching, C-H scissoring, $\mathrm{C}-\mathrm{H}$ wagging, $\mathrm{C}-\mathrm{H}$ twisting and a strong peak for ether (C-O-C) at $\mathrm{cm}^{-1}$ (Sundararajan et al., 2017).

The infrared spectra of S/P10oo blend did not show new peaks indicating that no new chemical bonds were formed.
However, an increase in intensity was observed at $\mathrm{O}-\mathrm{H}$ stretching for S/P10oo compared to sago film. From the spectrum, the $-\mathrm{OH}$ peak for sago film shifted to higher wavenumber from $3280 \mathrm{~cm}^{-1}$ to $3318 \mathrm{~cm}^{-1}$ when PEG-10oo was added indicating there is an interaction between starch and PEG. The O-H absorption for sago and PEG is attributed to self-hydrogen bonded hydroxyl groups (Fei et al., 2003). When PEG added into sago, this percentage of self-hydrogen bonding reduced caused by the formation of intermolecular hydrogen bonds between sago and PEG (Turhan et al., 2001). PEG with higher molecular weight would provide different types of interactions (Sun et al., 2008). Higher molecular weight PEG has opportunity to entangle with starch, but also would interact with PEG chain itself. This interaction affects mechanical strength of the films. The reaction scheme of sago and PEG is shown in Scheme 1.

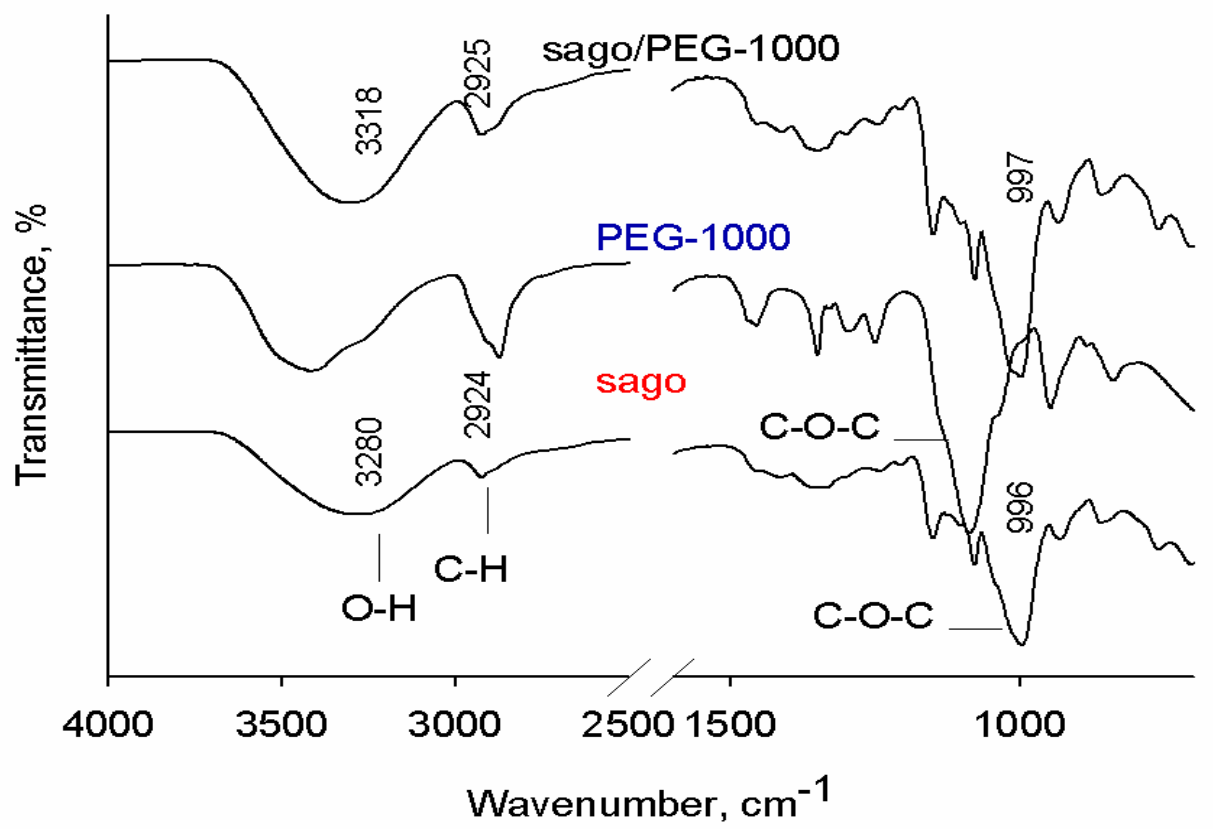

Figure 3. FTIR analysis for sago film (S), PEG-100o and a blend of sago and PEG-10oo (S/P100o) 


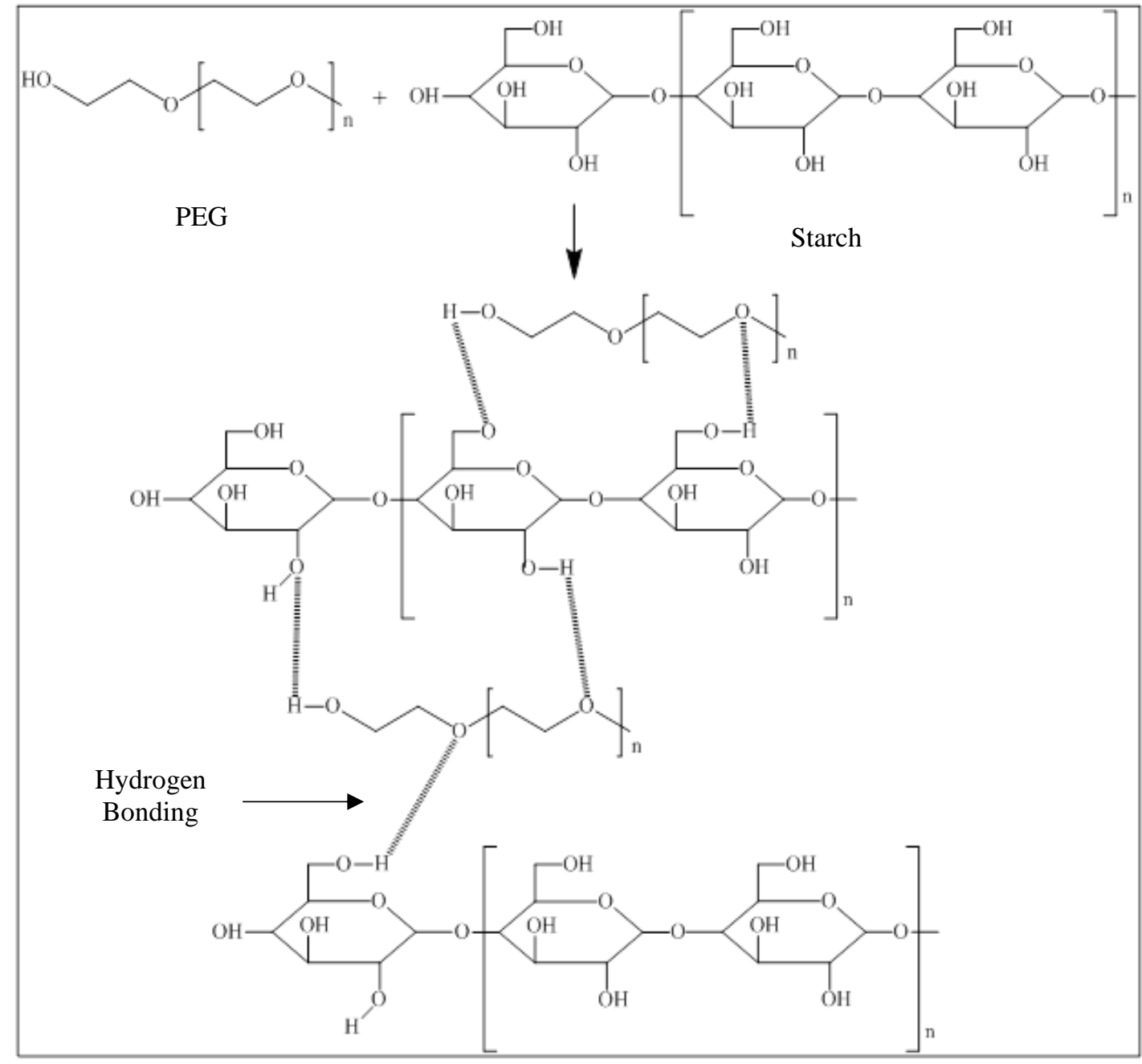

Scheme 1. A schematic diagram showing the hydrogen bonding between PEG and sago starch

\section{Tensile Properties}

Effect of molecular weight of PEG on thickness, tensile stress, Young's Modulus and percentage elongation of sago and its blend films are summarised in Table 1 . The addition of PEG400 and PEG-1000 increased the tensile stress from 33.51 $\mathrm{MPa}$ to 39.11 MPa and 43.51 MPa, respectively. However, the tensile strength of the film dropped to 42.83 MPa when PEG4000 was added. The addition of PEG-1000 increased Young's Modulus 25\% from 354 to $444 \mathrm{MPa}$. The higher the molecular weight, the lower Young's Modulus observed. On the other hand, the incorporation of PEG-400 increased the percentage elongation dramatically yet decreased by increasing molecular weight of PEG. This suggests that PEG with low molecular weight could be more effective as a plasticiser in sago starch film. Low molecular weight of PEG has shorter chain which allows it to be easier to insert between polymer chains consequently more influence on mechanical properties of film as compared to high molecular weight PEG (Sun et al., 2008). The decrease in stress and Young's Modulus could be due to the effect of reduction intermolecular bonding inside the network. PEG-400o has higher molecular weight and longer chain. Thus, it is difficult to dissolve in sago solution causing difficulty in hydrogen bond formation (Yu et al., 2015). 
Table 1. Thickness, stress at maximum, Young's modulus and elongation of starch film with different molecular weight of PEG 2 \% $/ \mathrm{w}$, (starch basis). Values were given as mean \pm standard deviation.

\begin{tabular}{ccccc}
\hline Sample & Thickness, mm & $\begin{array}{c}\text { Stress at } \\
\text { maximum, MPa }\end{array}$ & $\begin{array}{c}\text { Young's Modulus, } \\
\text { MPa }\end{array}$ & Elongation, \% \\
\hline S & $0.060 \pm 0.013$ & $33.51 \pm 3.60$ & $354.80 \pm 23.45$ & $4.35 \pm 3.60$ \\
S/P400 & $0.062 \pm 0.026$ & $39.11 \pm 5.93$ & $354.75 \pm 36.65$ & $11.52 \pm 2.40$ \\
S/P1000 & $0.064 \pm 0.011$ & $43.51 \pm 3.22$ & $444.34 \pm 32.47$ & $10.46 \pm 1.55$ \\
S/P4000 & $0.064 \pm 0.018$ & $42.83 \pm 2.18$ & $374.4 \pm 19.86$ & $10.00 \pm 0.83$ \\
\hline
\end{tabular}

The effect of amount PEG concentration was studied based on the mechanical properties of the starch films of $\mathrm{S} / \mathrm{P} 1000$ which was higher than that of S/P400 and S/P400o. The increase in PEG concentration up to $2 \% \mathrm{w} / \mathrm{w}$, enhanced the tensile stress to $43.51 \mathrm{MPa}$ (Figure 4). Further increased in concentration decreased the tensile stress. This occurs when the concentration exceeds its compatibility limit causing phase separation. At high concentration of PEG, the starch mixture did not dissolve completely because of incompatibility and increment in mobility of polymer chain (Luangtana-anan et al., 2010). Incorporation of PEG at low concentration increased Young's modulus. With increasing concentration of PEG, Young's modulus decreased indicating that the film lost its stiffness. The increasing of PEG content caused a significant increase in elongation up to $2 \%$ of PEG concentration and decreased with further increasing of PEG concentration. Plasticisers promote the mobility between the molecular chains. However, at high concentration, separation phase happened thus resulted in a decrease in flexibility (Muscat et. al., 2012; Jantrawut et al., 2017). This is supported by morphological study as shown in a small picture in Figure 6. Besides, the increase in PEG concentration increased the moisture content as shown in Figure 2 which also contributed to the reduction of tensile stress of the films.

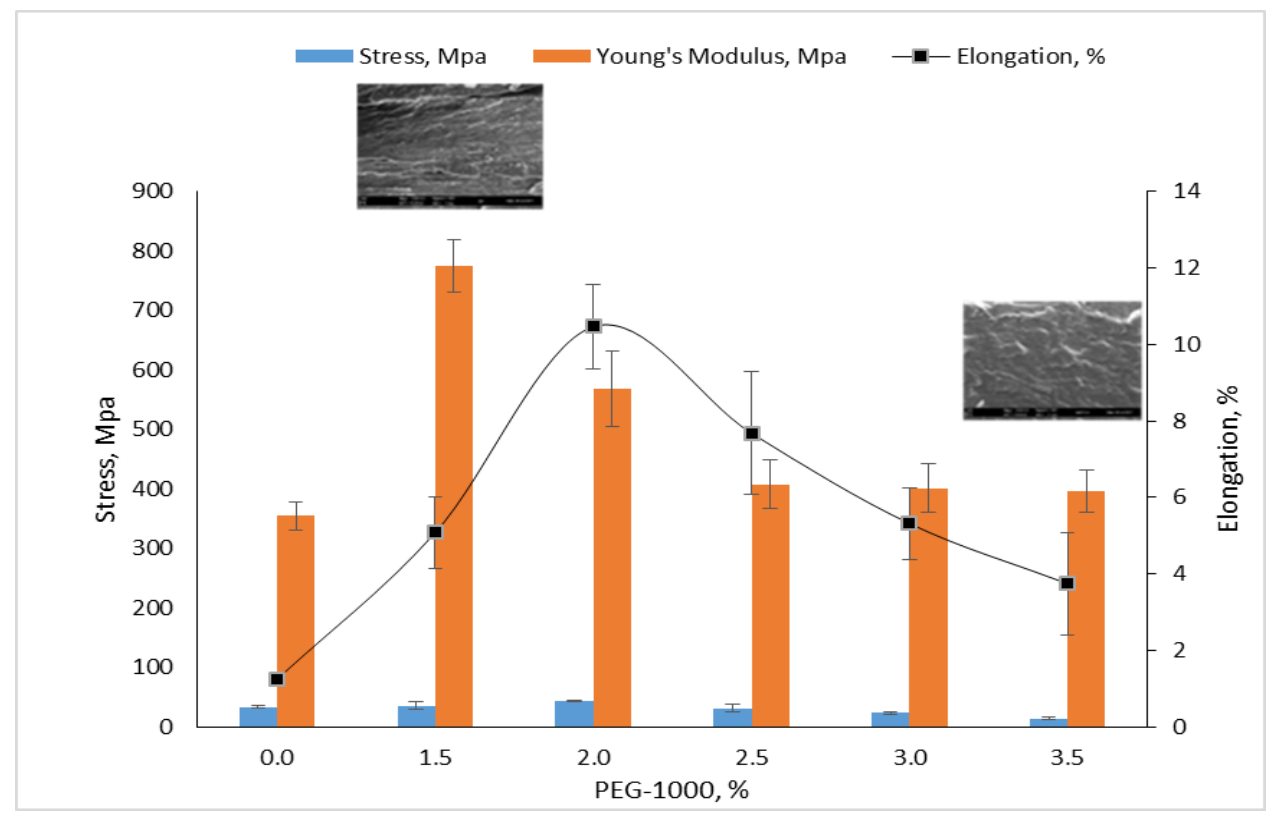

Figure 4. Stress, Young's Modulus and elongation sago film and its blends as a function of different concentration of PEG1000. Small pictures indicate cross section micrograph of the films as examined under FE-SEM. 
Figure 5 shows the effect of molecular weight and different concentration of PEG on light transmittance of sago films. All films exhibit transparent properties but reduced when PEG4000 incorporated into sago starch because of its high molecular weight and incompatibility (Figure 5a). Meanwhile, an increase in the concentration of PEG resulted in opaquer S/P10oo film as depicted in Figure 5b. A study

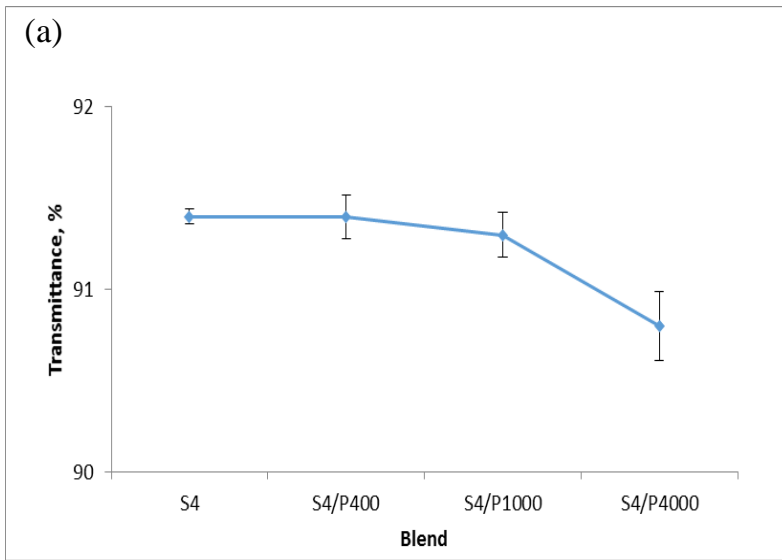

done by Laohakunjit \& Noomhorm (2004) found the addition of more than $6 \%$ w/w PEG displayed white, opaque appearance and brittle. This is due to phase separation and incompatibility of PEG and rice starch at higher concentration of PEG. This refers to as "blooming" and "blushing". Similar observation also reported by Saber et al. (2017) and Nawab et al. (2016).

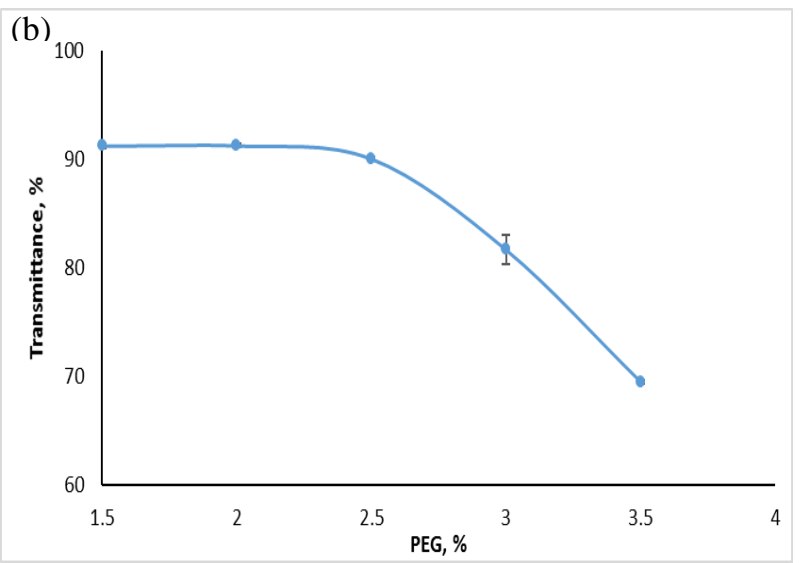

Figure 5. Effect of (a) molecular weight of PEG and (b) different concentration of PEG on light transmittance of $\mathrm{S} / \mathrm{P} 1000$ films

\section{Morphology Study}

The cross section and surface morphology of the film was investigated by FE-SEM as shown in Figure 6. Film without PEG shows irregular and rough surface as can be seen from Figure 6(a). The addition of PEG-400 created a smoother surface (Figure 6b). This is explained by the presence of PEG that acted as a plasticiser to reduce the intermolecular force and increase the mobility of the polymer chains. Meanwhile, the film structure becomes slightly dense and the existence of cavities decreased when PEG-100o is added into the film (Figure 6c). Nevertheless, the film with PEG-400o exhibited non-uniform surface due to longer chain and larger molecular size causing difficulty in inserting into the polymer network as displayed in Figure 6(d). Thus, it resulted in a less homogenous blend. This phenomenon explained the reason for decreasing in tensile stress, percentage elongation and light transmittance of the film as explained before.

To further investigate the morphology, the cross section of the films was also examined. The film without plasticiser showed brittle characteristic with uneven surface and some pores occurred as represents in Figure 6(a). Incorporation of PEG-400o displayed a sign of immiscible blend and aggregation as well as phase separation. A more compact structure also displayed from $\mathrm{S} / \mathrm{P} 4000$. This observation was supported by Pivsa-Art et al. (2016) and Khan et al. (2017). As displayed in Figure 6(d), the S/P4000 shows brittle behavior, hence exhibited poor mechanical properties. 


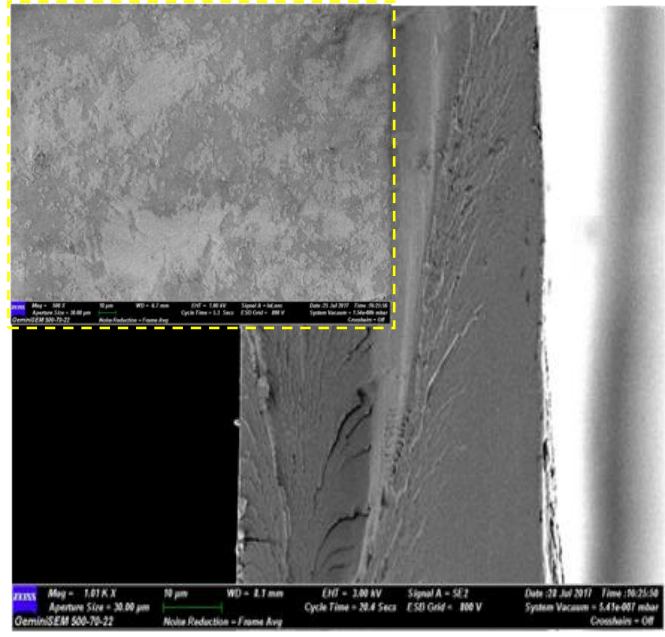

(a)

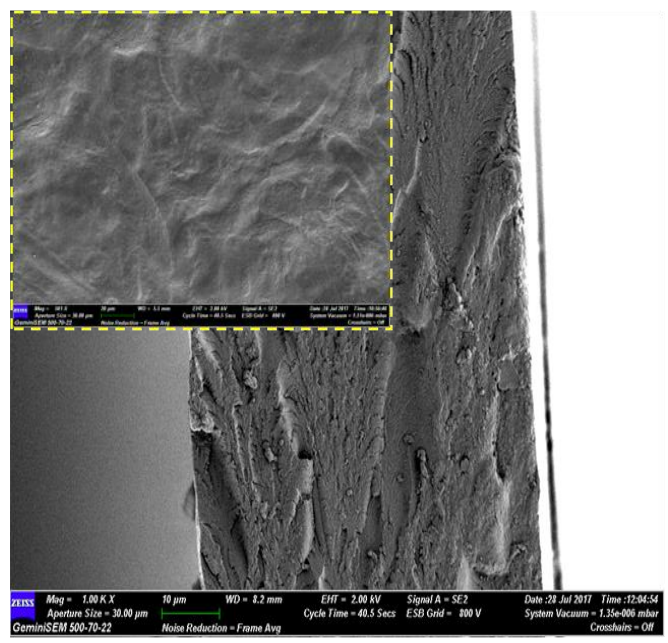

(c)

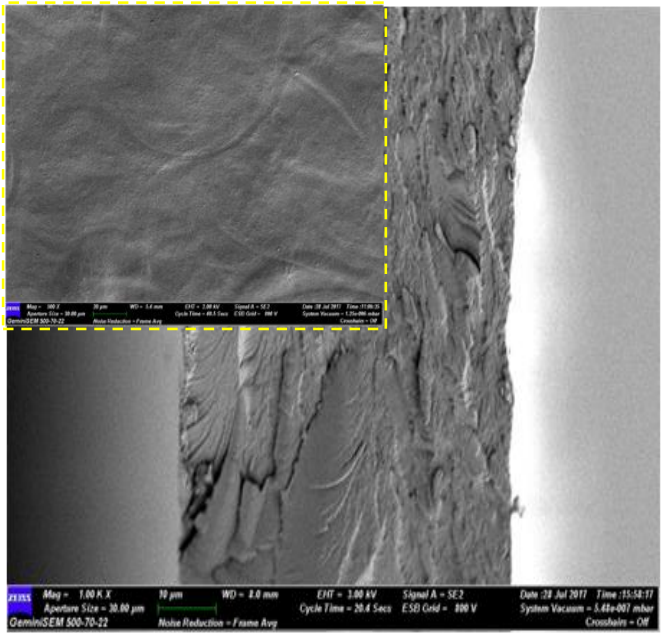

(b)

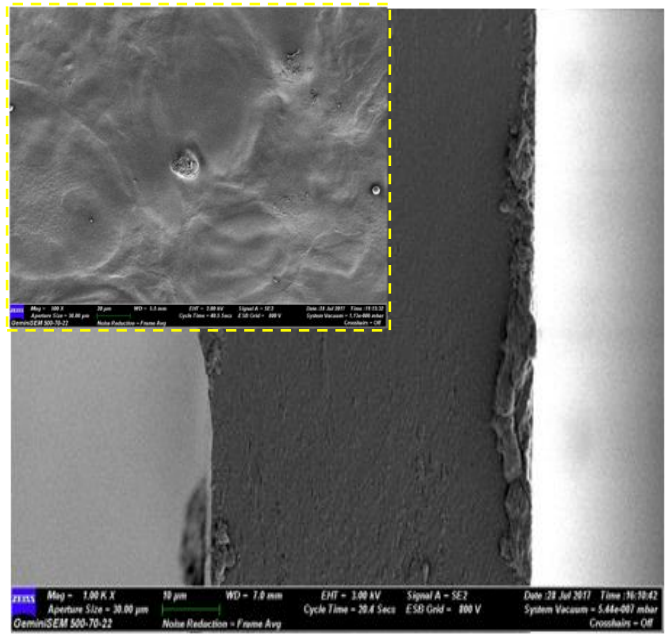

(d)

Figure 6. FESEM micrograph for cross section (a) sago film without plasticiser, S (b) S/P40o, (c) S/P100o and (d) $\mathrm{S} / \mathrm{P} 4000$ at $1000 \times$. Small picture indicates micrograph for surface of the films at $500 \times$

\section{CONCLUSION}

The incorporation of PEG resulted in a good effect on the mechanical properties of sago film. PEG with low molecular weight displayed an increase in tensile stress and percentage elongation as compared to unplasticised sago film. At a high concentration of PEG, the mechanical properties of the sago films decreased. Meanwhile, the appearance of the film became opaque when the concentration of PEG more than 2 $\% w / w$. Based on tensile stress, Young's modulus and percentage elongation, PEG-100o at the concentration of 2 $\% w / w$ was the best plasticiser among the studied PEG for sago starch film.

\section{ACKNOWLEDGEMENT}

The authors would like to thanks to Universiti Kebangsaan Malaysia and Malaysia Nuclear Agency for using their facilities throughout of this work. 


\section{REFERENCES}

Abdorreza, MN, Robal, M, Cheng, LH, Tajul, AY \& Karim, AA 2012, 'Physicochemical, thermal, and rheological properties of acid-hydrolyzed sago (Metroxylon sagu) starch', LWT-Food Science and Technology, vol. 46, no.1, pp. 135-141.

Aminian, M, Nafchi, AM, Bolandi, M \& Alias, AK 2013, 'Preparation and characterization of high degree substituted sago (Metroxylon sagu) starch with propylene oxide', Starch-Stärke, vol. 65, no7-8, pp. 686-693.

Bujang, KB, Apun, K \& Salleh, MA 1996, 'A study in the production and bioconversion of sago waste', Sago: The future Source of Food and Feed, Riau University Press, Indonesia, pp. 195-201.

Davis, G \& Song, JH 2006, 'Biodegradable packaging based on raw materials from crops and their impact on waste management', Industrial crops and products, vol. 23, no. 2, pp. 147-161.

Fei, B, Chen, C, Wu, H, Peng, S, Wang, X \& Dong, L 2003, 'Quantitative FTIR study of PHBV/bisphenol: A blends', European Polymer Journal, vol. 39, no. 10, pp. 1939-1946.

Ismail, H \& Zaaba, NF 2012, 'Tensile properties, degradation behavior, and water absorption of sago starch plastic films', Journal of Vinyl and Additive Technology, vol. 18, no. 4, pp. 235-240.

Jamingan, Z, Ahmad, MB, Hashim, K \& Zainuddin, N 2015, 'Sago starch based hydrogel prepared using electron beam irradiation technique for controlled release application', Malaysian J Anal Sci, vol. 19, no.3, pp. 503512.

Jantrawut, P, Chaiwarit, T, Jantanasakulwong, K, Brachais, CH \& Chambin, O 2017, 'Effect of plasticizer type on tensile property and in vitro indomethacin release of thin films based on low-methoxyl pectin', Polymers, vol. 9, no. 7, pp. 289-303.

Kang, HJ \& Min, SC 2010, 'Potato peel-based biopolymer film development using high-pressure homogenization, irradiation, and ultrasound', LWT-Food Science and Technology, vol. 43, no. 6, pp. 903-909.

Karim, AA, Tie, APL, Manan, DMA \& Zaidul, ISM 2008, 'Starch from the sago (Metroxylon sagu) palm treeproperties, prospects, and challenges as a new industrial source for food and other uses', Comprehensive Reviews in Food Science and Food Safety, vol. 7, no. 3, pp. 215-228.
Khan, A, Niazi, MBK, Naqvi, SR \& Farooq, W 2017, 'Influence of plasticizers on mechanical and thermal properties of methyl cellulose-based edible films', Journal of Polymers and the Environment, vol. 26, no. 1, pp. 291-300.

Kim, CH, Kim, DW \& Cho, KY 2009, 'The influence of PEG molecular weight on the structural changes of corn starch in a starch/PEG blend', Polymer bulletin, vol. 63, no. 1, pp. 91-99.

Kowalczyk, D, Gustaw, W, Świeca, M \& Baraniak, B 2014, 'A study on the mechanical properties of pea protein isolate films', Journal of Food Processing and Preservation, vol. 38 no. 4, pp. 1726-1736.

Laohakunjit, N \& Noomhorm, A 2004, 'Effect of plasticizers on mechanical and barrier properties of rice starch film', Starch-Stärke, vol. 56, no. 8, pp. 348-356.

Luangtana-anan, M, Nunthanid, J \& Limmatvapirat, S 2010, 'Effect of molecular weight and concentration of polyethylene glycol on physicochemical properties and stability of shellac film', Journal of Agricultural and Food Chemistry, vol. 58, no. 24, pp. 12934-12940.

Ma, X, Chang, PR, Yu, J \& Stumborg, M 2009, 'Properties of biodegradable citric acid-modified granular starch/thermoplastic pea starch composites', Carbohydrate Polymers, vol. 75 , no. 1, pp. 1-8.

Mali, S, Grossmann, MVE, Garcia, MA, Martino, MN \& Zaritzky, NE 2002, 'Microstructural characterization of yam starch films' Carbohydrate Polymers, vol. 50, no. 4, pp. 379-386.

Muscat, D, Adhikari, B, Adhikari, R \& Chaudhary, DS 2012, 'Comparative study of film forming behaviour of low and high amylose starches using glycerol and xylitol as plasticizers,' Journal of Food Engineering, vol. 109, no. 2, pp. 189-201.

Nawab, A, Alam, F, Haq, MA \& Hasnain, A 2016, 'Biodegradable film from mango kernel starch: Effect of plasticizers on physical, barrier, and mechanical properties', Starch-Stärke, vol. 68, no. 9-10, pp. 919-928.

Nouri, L \& Nafchi, AM 2014, 'Antibacterial, mechanical, and barrier properties of sago starch film incorporated with betel leaves extract', International Journal of Biological Macromolecules, vol. 66, pp. 254-259.

Pirsa, S, Mohtarami, F \& Kalantari, S 2002, 'Preparation of biodegradable composite starch/tragacanth gum/nanoclay film and study of its physicochemical and mechanical 
properties', Chemical Review and Letters, vol. 3, no. 3, pp. 98-103.

Pivsa-Art, W, Fujii, K, Nomura, K, Aso, Y, Ohara, H \& Yamane, H 2016, 'The effect of poly (ethylene glycol) as plasticizer in blends of poly (lactic acid) and poly (butylene succinate)', Journal of Applied Polymer Science, vol. 133, no. 8, pp. 1-10.

Saberi, B, Thakur, R, Vuong, QV, Chockchaisawasdee, S, Golding, JB, Scarlett, CJ \& Stathopoulos, CE 2016, 'Optimization of physical and optical properties of biodegradable edible films based on pea starch and guar gum', Industrial Crops and Products, vol. 86, pp. 342-352.

Saberi, B, Chockchaisawasdee, S, Golding, JB, Scarlett, CJ \& Stathopoulos, CE 2017, 'Physical and mechanical properties of a new edible film made of pea starch and guar gum as affected by glycols, sugars and polyols', International Journal of Biological Macromolecules, vol. 104, pp. 345-359.

Sahari, J, Sapuan, SM, Zainudin, ES \& Maleque, MA 2014, 'Biodegradability and mechanical behaviour of sugar palm starch based biopolymer', American Journal of Applied Sciences, vol. 11, no. 10, pp. 1836-1840.

Sundararajan, S, Samui, AB \& Kulkarni, PS 2017, 'Shapestabilized poly (ethylene glycol) (PEG)-cellulose acetate blend preparation with superior PEG loading via microwave-assisted blending', Solar Energy, vol. 144, pp. 32-39.

Sun, G, Zhang, X-Z, \& Chu, C-C 2008, 'Effect of the molecular weight of polyethylene glycol (PEG) on the properties of chitosan-PEG-poly(N-isopropylacrylamide) hydrogels', Journal of Materials Science: Materials in Medicine, vol. 19, no. 8, pp. $2865-2872$.

Suppakul, P, Chalernsook, B, Ratisuthawat, B, Prapasitthi, S \& Munchukangwan, $\mathrm{N}$ 2013, 'Empirical modeling of moisture sorption characteristics and mechanical and barrier properties of cassava flour film and their relation to plasticizing-antiplasticizing effects', LWT-Food Science and Technology, vol. 50, no. 1, pp. 290-297.

Turhan, KN, Sahbaz, F \& Güner, A 2001, 'A spectrophotometric study of hydrogen bonding in methylcellulose-based edible films plasticized by polyethylene glycol', Journal of Food Science, vol. 66, no. 1, pp. 59-62.

Yaacob, B, Mohd, AMCI, Hashim, K \& Abu, BB 2011, 'Optimization of reaction conditions for carboxymethylated sago starch', Iranian Polymer Journal, vol. 20, no. 3, pp. 195-204.
Yu, Y, Cheng, Y, Ren, J, Cao, E, Fu, X \& Guo, W 2015, 'Plasticizing effect of poly (ethylene glycol) s with different molecular weights in poly (lactic acid)/starch blends', Journal of Applied Polymer Science, vol. 132, no. 16, pp. 19.

Zailan, Z, Yaakob, N \& Badri, KH 2017, 'Bioplastics from starch of Sago Metroxylon Spp. reinforced polyethylene glycol', Undergrad. Res. J. Renew. Chem., no. 1, pp. 31-38. 